\title{
Melatonin Avoids Anatomofunctional Changes Associated to Aging in a Rat Model
}

\author{
Bertha Prieto Gómez, Cruz Reyes-Vázquez, Mireya Velázquez-Paniagua \\ Departamento de Fisiología, Facultad de Medicina, UNAM, México D.F., México \\ Email: prieto@unam.mx
}

Received 14 July 2014; revised 16 August 2014; accepted 13 September 2014

Copyright $@ 2014$ by authors and Scientific Research Publishing Inc.

This work is licensed under the Creative Commons Attribution International License (CC BY). http://creativecommons.org/licenses/by/4.0/

(c) (i) Open Access

\begin{abstract}
Melatonin is a hormone synthesized and released primarily by the pineal gland. Its secretion follows a circadian rhythm with a peak overnight. Its secretion is initiated approximately to the three months of age and continues to rise during the childhood. Previous to the puberty there is a decrease of melatonin secretion that continues until the old age. Melatonin has effects in the body and acts through at least four mechanisms: membrane receptors, orphan nuclear receptors, calmodulin and free radicals. It has been suggested that aging can be a consequence of the oxidation of cells that eventually become vulnerable to injury and die. This work reviews the antioxidant effects of melatonin in a rodent model, on the formation of free radicals, on the MAP2 protein expression and on the electrophysiology of the hippocampus at different ages. The results indicate that melatonin maintains in a "best" state to the experimental animals compared to controls. It suggests the use of melatonin as a therapy to prevent or delay the aging effects on the cells.
\end{abstract}

\section{Keywords}

Rat, Melatonin, Hippocampus, Antioxidant, Aging

\section{Introduction}

Melatonin (N-acetyl-5-methoxytryptamine) is ubiquitously distributed, even when this is produced primarily by the pineal gland. This molecule is involved in a number of biological and physiological aspects of the body functions. This indole is also found in fruits and vegetables such as cherries and tomatoes among others, in which it may have an important role in the maturation [1].

Melatonin is a natural hormone secreted in humans [2]-[5] with a circadian rhythm, its values increase during the darkness [6]-[8]. This indol derives from serotonin which in turn comes from tryptophan. The pathway from serotonin to melatonin implicates two enzymes that are activated during the night; the arylalkylamine $\mathrm{N}$-acetyl- 
transferase (limiting step in the reaction) and hydroxyindole-O-methyltransferase (HIOMT) (Figure 1). Melatonin is metabolized in the liver and urinary excreted as 6-sulfatoxymelatonin [9] [10].

Melatonin secretion: Humans melatonin has a rate that is in accordance with the light-dark cycle. Its secretion increases soon after the onset of darkness, and peaks between 2 and 4 a.m. And gradually falls during the second half of the night [11]. The melatonin amount varies according to age. Infants younger than three months of age secrete very little melatonin. Melatonin increases its plasma levels and becomes a circadian rhythm during childhood, reaching a peak before the puberty onset, at this stage starts down, drop that has been suggested marks the release of sex hormones [5], this decrease continues until old age [11]. Melatonin has a seasonal variation in humans and in some mammals [12] [13].

Melatonin levels are associated with sleep and some studies suggest that melatonin may also be effective in avoiding some types of cancer and some chronic pathologies associated to the age such as Alzheimer. So, it has been suggested that some neurodegenerative diseases may result from a significant decrease in melatonin levels during aging [14] [15].

At less four mechanisms of melatonin's action has been described:

1) Through binding to membrane receptors, $\mathrm{MT}_{1}$ (Mel1a), $\mathrm{MT}_{2}$ (Mel1b) and $\mathrm{MT}_{3}\left(\mathrm{Mel1} 1_{\mathrm{C}}, M T N R 1 C\right.$ ). The $\mathrm{MT}_{1}$ and $\mathrm{MT}_{2}$ are found in human and in several mammals, while $\mathrm{MT}_{3}$ has been identified in fish, amphibian and birds. Additionally, exists an orphan G protein-coupled receptor, GPR50, which shares $45 \%$ amino acid sequence identity with $\mathrm{MT}_{1}$ and $\mathrm{MT}_{2}$ [16], but its function is not fully understood. GPR50 does not bind to melatonin at all [17]. All of them trigger a cascade of signals via a protein G [18] [19]. They are expressed on several CNS parts (nucleus accumbens, suprachiasmatic nucleus, hippocampus, cerebellar cortex, prefrontal cortex, basal ganglia, substantia nigra, ventral tegmental area, and retinal and in peripheral organs (blood vessels, mammary gland, gastrointestinal tract, liver, kidney and bladder, ovary, testis, prostate, skin and to the immune system). Melatonin receptors mediate a big number of physiological effects, for example, blood pressure regula-

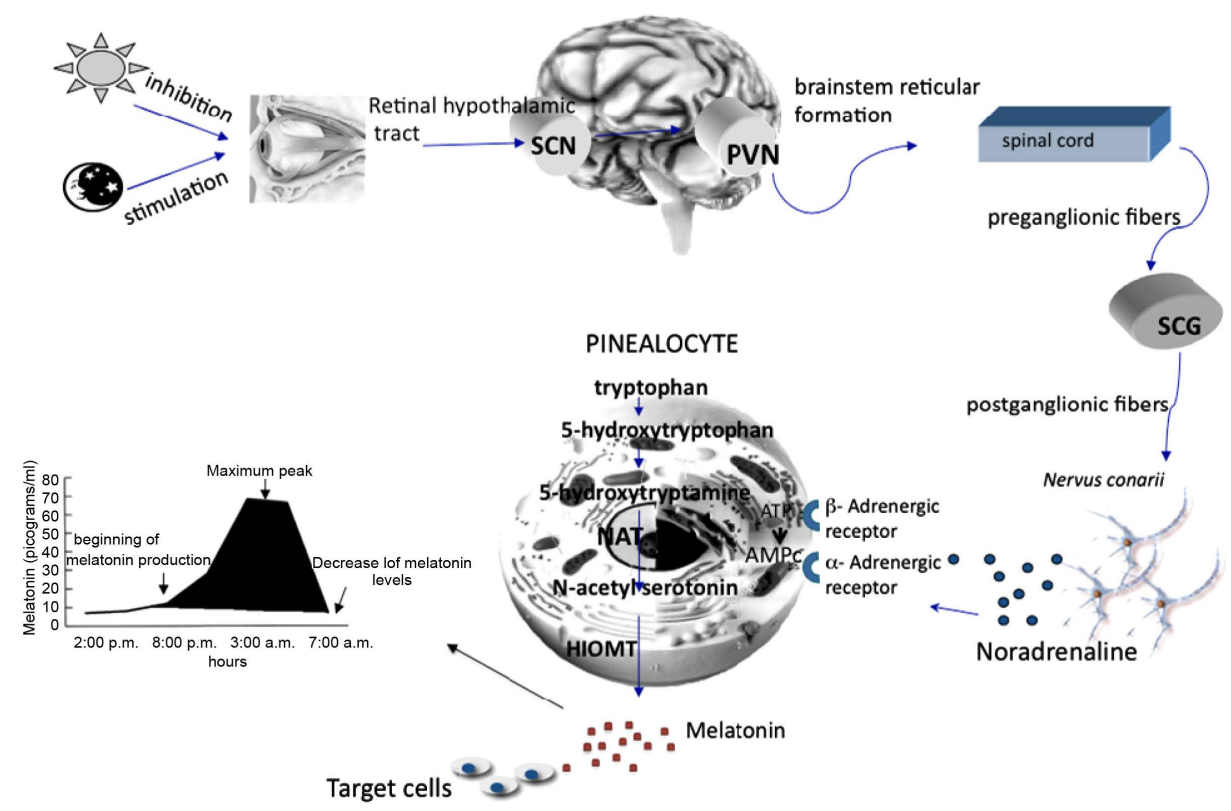

Figure 1. Melatonin synthesis. During night nerve signals traveling through the optic nerve reach the suprachiasmatic nucleus (SQN), paraventricular nucleus (NPV), and the spinal cord this connects with the superior cervical ganglia ending in the nervus conarii where noradrenaline (NA) is release. Once noradrenaline binds its alpha and beta receptors in the pinealocyte, synthesis of cAMP and the activation of the enzyme protein kinase $\mathrm{C}$ (PKC) are induced, initiating a cascade of protein phosphorylation to promote transcription and translation of the $\mathrm{N}$-acetyltransferase protein (NAT), the rate limiting enzyme in the synthesis of melatonin. Finally, the $\mathrm{N}$-acetilserotonina melatonin is transformed through the enzyme hidroxiortometiltransferasa (HIOMT). Once released into the plasma, melatonin is capable of binding to different target sites. The graph shows the peak levels reached in human melatonin secreted by the pineal gland at night, this is about $70 \mathrm{pg} / \mathrm{mL}$. 
tion [17] [20], seasonal reproduction [21] and oncogenesis [22] [23].

The receptors' sensitivity to specific cues fluctuates throughout the 24-hour cycle, and this sensitivity can be modulated in a homologous fashion, that is, by melatonin itself, and in a heterologous manner by other cues including the photoperiod or the estrogens [24].

2) Melatonin also may modulate cellular activity through a nuclear receptor, its biological action through nuclear signaling involving retinoid acid receptor-related orphan RZR/ROR receptors. The RZR/ROR receptors belong to a subclass of orphan nuclear receptors with three subtypes (a, b, and c). RZR/RORa is expressed almost ubiquitously in all tissues, while RZR/RORb is restricted to the brain, and finally, RZRc is expressed preferentially in skeletal muscle but also in the thymus, testis, prostate, pancreas, liver, and heart. This indol regulates cell processes, via nuclear signaling, through RZR/ROR transcription factors, which, in turn, regulate key genes involved in neuroinflammatory pathways (5-lipoxygenase), cell-differentiation, and cellular senescence (p21WAF1/C1P1), (lipid metabolism (apolipoprotein A-1), cell-cycle arrest and apoptosis (N-myc), and $\mathrm{Ca}^{2+}$ channel modulator functions in cerebellum (Purkinje cell protein) [25].

3) Melatonin and calmodulin: Another possible mechanism of action of melatonin is through modulation of the intracellular calcium concentrations. Melatonin regulates calcium channels and intracellular signaling through its binding to calmodulin [25] [26] and interacting with target enzymes as phosphodiesterase and structural proteins [11] [27] [28]. So, melatonin acts as a calmodulin antagonist [11]. It has been supported the hypothesis that under physiological conditions, melatonin synchronizes different body rhythms through cytoskeletal rearrangements mediated by its calmodulin antagonism [29].

4) Melatonin and free radicals: Melatonin is considered as a potent free radical scavenger and an indirect antioxidant [30]-[32]. It has protective action in various models of oxidative stress [33] [34]; it is an effective hydroxyl radical $(\mathrm{OH})$ scavenger [35] and detoxifies other reactive oxygen and nitrogen species including single oxygen [36]-[39]. Moreover, melatonin stimulates the activities of enzymes that metabolize reactive species [40] [41]. Melatonin is a highly lipophilic molecule and has the ability to cross all the morphological barriers, including the blood-brain barrier, allowing enter every part of the cells where it can prevent oxidative damage and preserve mitochondrial function [30]. Melatonin also has been postulated as a molecule able of retarding brain aging [39] [42]. This pineal indol significantly declines with aging, for this reason, it has been suggested that age related neurodegenerative diseases, as Alzheimer's disease, may be related to melatonin deficiency [25] [43].

Considering the previous data in our laboratory has been investigated the melatonin role in some aging mechanisms.

\subsection{Melatonin and Free Radicals during the Hippocampal Aging}

In a first work, in male Wistar rats kept in laboratory conditions, regulated temperature $\left(25^{\circ} \mathrm{C} \pm 2{ }^{\circ} \mathrm{C}\right)$, light (12:12 h light/dark cycle) and free access to chow and tap water. Melatonin (1 mg/Kg, body weight) was applied for several months to an experimental group while the control group only received the melatonin's vehicle. Amount of free radicals was obtained by electronic paramagnetic resonance from hippocampus at 6,10 , and 14 months of melatonin treatment. The results indicate that increasing the age there is a directly proportional increase in free radicals in the hippocampus and even though this increase of free radicals in the hippocampus was higher in control rats than in the experimental group, differences resulted significant only at 14 months of treatment [44] (Table 1).

\subsection{Melatonin and MAP2 Protein Staining during the Hippocampal Aging}

Using data that melatonin reduced free radicals in rat hippocampus, arise the idea that this decrease in cellular

Table 1. The table shows the concentration of free radicals measured by electron paramagnetic resonance (EPR) in the hippocampus of control and melatonin treated rats for 6,10 and 14 months. A decrease of free radicals concentration was found in the different months of treatment in the melatonin treated rats compared to control, resulting in a significant difference to the fourteen months. ${ }^{*} \mathrm{p}<0.001$.

\begin{tabular}{ccc}
\hline Months of Treatment & Control & Melatonin \\
\hline 6 & $8.7 \times 10^{-9} \pm 5.7 \times 10^{-9}$ & $4.2 \times 10^{-9} \pm 9.8 \times 10^{-9}$ \\
10 & $4.5 \times 10^{-8} \pm 1.46 \times 10^{-8}$ & $3.7 \times 10^{-8} \pm 2.2 \times 10^{-9}$ \\
14 & $8.6 \times 10^{-8} \pm 7.1 \times 10^{-9}$ & $6.4 \times 10^{-9} \pm 4.8 \times 10^{-9 *}$ \\
\hline
\end{tabular}


oxidation also would reduce cell death and therefore the hippocampal neuronal loss in rats treated with melatonin. So in rats treated with melatonin for several months, the amount of structural proteins MAP2 was analyzed by hippocampal staining. The results revealed that the staining for MAP2 was significantly higher for melatonin treated rats than the controls, both 6 and 12 months of treatment. However it was not possible to determine whether the increased staining was the result of a decrease in neuronal loss in rats treated with melatonin or the increase for a new formation of neuronal processes [45] (Table 2).

\subsection{Melatonin and Unitary Spontaneous Neuronal Activity in the Hippocampus during Aging}

If melatonin preserved the hippocampal cytoarchitecture by a reduction of free radicals was of interest determine if the electrophysiology of this structure is maintained as an indicator of a good functional status.

Melatonin treated rats exhibited an increased amount of spontaneous unitary activity in the hippocampus at all ages tested, 2, 4, 6 and 8 months of treatment. The experimental rats showed an increased number of cells with bursts activity while most of the control rats showed single spikes. In the control rats, the neural firing rate was very similar to the 2, 4 and 6 months and decreased with the age of 8 months of treatment and was always lesser than that of the experimental rats. Experimental rats exhibited a higher and a greater dispersion of activity than that found in control rats with significant differences at 8 months of treatment [46] (Table 3).

It should be mentioned that all the control rats used in the different experiments, about a year and a half old started to have a brown color necklace around his neck, that collar is not observed in animals treated with melatonin and they look younger than control rats (Figure 2).

\section{Discussion}

Aging is a progressive and multifaceted process that includes gradual cellular loss, endocrine and metabolic deficits, decreasing defense mechanisms and there are functional losses which contribute to health deterioration and finally to death. During this procedure there is a general decline in nervous system functions due to structural, molecular, biochemical and physiological changes [47].

Melatonin is an indol derivate, principally, from the pineal gland, involved in numerous biological and physiological body functions. The synthesis and liberation of this hormone are stimulated by darkness and this acts through at least four mechanisms: the G protein coupled receptors, nuclear orphan receptors, calmodulin and free radicals.

Free radicals and other reactive oxygen and nitrogen species are generated in vivo, as result of the metabolic cell activities. The levels of free radicals are controlled by antioxidant defenses, which reduce oxidative damage to biomolecules avoiding the tissue injury.

Table 2. The table shows the results of semi quantitative densitometry analysis (light transmittance, arbitrary units). For both areas, CA1 and CA3 of the hippocampus. There was a significant increase at 6 and 12 months in rats treated with melatonin compared with the control group. ${ }^{*} \mathrm{p}<0.001$.

\begin{tabular}{ccccc}
\hline Hippocampal areas & Control Months 6 & Melatonin Months 6 & Control Months 12 & Melatonin Months 12 \\
\hline CA 1 & $88 \pm 2.0$ & $97 \pm 2^{*}$ & $45 \pm 1.5$ & $65 \pm 3.0^{*}$ \\
CA 3 & $86 \pm 2.0$ & $107 \pm 2^{*}$ & $58 \pm 1.0$ & $78 \pm 3.0^{*}$ \\
\hline
\end{tabular}

Table 3. the table shows the average normalized firing rate in control and melatonin treated rats at 4 different ages, even there was an increase in the firing rate at the tested ages; there is only significant difference at 8 months of treatment compared to the control. ${ }^{*} \mathrm{p}<0.005$.

\begin{tabular}{ccc}
\hline Months of Treatment & Control & Melatonin \\
\hline 2 & $0.1141 \pm 0.0288$ & $0.1398 \pm 0.0329$ \\
4 & $0.1156 \pm 0.0205$ & $0.1862 \pm 0.0358$ \\
6 & $0.1227 \pm 0.0295$ & $0.2191 \pm 0.0531$ \\
8 & $0.1043 \pm 0.0351$ & $0.2183 \pm 0.0371^{*}$ \\
\hline
\end{tabular}




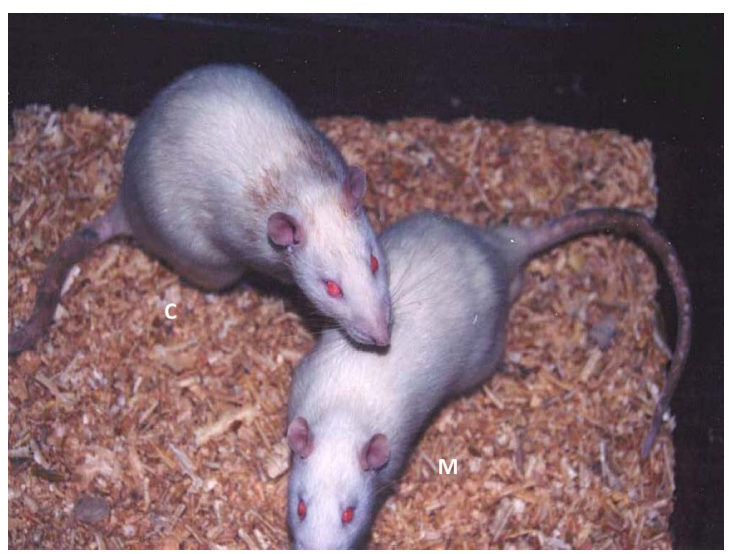

Figure 2. The photograph shows two rats of 14 months of daily treatment with melatonin (M, $1 \mathrm{mg} / \mathrm{kg}$ ) or melatonin's vehicle $(\mathrm{C})$. Rats treated with melatonin showed whiter, silky soft fur, than control rat, in which, the hair was thicker, rough and most of the rats in the control group showed a brown necklace and also brown color in some places of their body.

Melatonin has a powerful anti-oxidant action [35] [48] [49] as it has been shown to scavenge different types of free radicals in vitro, in body fluids and in cells [26]. Furthermore, melatonin plays an important role in activating anti-oxidant defenses such as the activation of the superoxide dismutase, catalase, glutathione peroxidase, glutathione reductase and glucose-6-phosphate dehydrogenase [50] [51]; both effects allow melatonin to reduce oxidative damage to the cells. Some studies have shown that melatonin has better antioxidant effects than other antioxidants [52], melatonin has been found to be more efficient than vitamin C in reducing the extent of oxidative stress in a model of Alzheimer's disease and also melatonin was found to reduce markers of oxidative stress more than E vitamin in mice [53]. These effects may result from the ability of melatonin to cross all cellular membranes. The decrease in night time serum melatonin concentrations that occurs with aging, suggest that melatonin antioxidative actions are also reduced. Studies in rats and mice suggest that diminished melatonin secretion may be associated with an acceleration of the aging process [54]. In our laboratory it was determined by Electronic Paramagnetic Resonance that there is a parallel increase in free radical concentration with age in the hippocampus of the Wistar rat in all the tested ages and that melatonin chronic application reduces such increase, so in this experiment an antioxidant effect of melatonin was found in the whole animal.

In addition it has be seen neuroprotective effects of melatonin in various regions of the central nervous system. It has been demonstrated an antioxidant effect of melatonin in the spinal cord, optic nerve and brain, with the most potent effects seen in the spinal cord white matter [53]. We be certain of that most of MAP2 staining that was found in the hippocampus of rats treated with melatonin is the result of that this hormone maintains a "good cytoarchitecture" in the hippocampus, which in turn would keep the cognitive function associated with this structure, as has been observed in Alzheimer's Disease patients treated with melatonin in whom there is a reduction in the cognitive decline [25].

In our work in which we analyzed the chronic application of melatonin on the electrophysiological activity from hippocampus, the increase elicited by melatonin in the firing rate could result by reducing the free radicals, maintaining the anatomic architecture and probably by modifying the signalization mechanisms, as the calcium dynamics, however this assertion must be studied in the complete animal.

Melatonin application in aged animals can protect the electrophysiological activity which could preserve the mechanisms necessary for memory formation and reduce the alterations in this parameter observed in old patients.

Color changes in the rat hair associated with aging were not observed in melatonin treated rats, while it was evident in the control rats; it clearly indicates that this hormone plays a key role in maintaining the skin and coat in this rodent which is not necessarily true for human. Several studies had showed no changes in the coloration of the skin of patients treated with the hormone [55], in our model was very evident that the brown necklace associated with aging does not appear in animals treated with melatonin, this would imply a significant participa- 
tion of this indol in the melanogenesis [56].

Melatonin for its antioxidant activities could be used as a dietary supplement to delay or prevent changes associated with age, however it would be preferable to ingest this indole after the reproductive stage of the individual because it had been reported that women could have reproduction alterations by consumption of melatonin [57] and there was a decrease in sperm motility in human [58] and in our laboratory it was observed that in the Wistar rat there was a significant change in the testicular architecture and fertility [59].

It will be an important issue of future research to investigate the role of melatonin in human biology, the clinical efficacy and safety of melatonin under different normal and pathological situations.

\section{References}

[1] Sierra, R. (2010) Concentrations and Profiles of Melatonin and Serotonin in Fruits and Vegetables during Fruit Ripening: A Mini-Review. Nature Precedings.

[2] Karasek, M. and Winczyk, K. (2006) Melatonin in Humans. Journal of Physiology and Pharmacology, 57, 19-39.

[3] Campos, C.I., Nogueira, C.H. and Fernandes, L. (2013) Aging, Circadian Rhythms and Depressive Disorders: A Review. American Journal of Neurodegenerative Disease, 2, 228-246.

[4] Tan, D.-X., Manchester, L.C., Fuentes-Broto, L., Paredes, S.D. and Reiter, R.J. (2011) Significance and Application of Melatonin in the Regulation of Brown Adipose Tissue Metabolism: Relation to Human Obesity. Obesity Reviews, 12, 167-188. http://dx.doi.org/10.1111/j.1467-789X.2010.00756.x

[5] Sánchez-Barceló, E.J., Mediavilla, M.D., Tan, D.X. and Reiter, R.J. (2010) Clinical Uses of Melatonin: Evaluation of Human Trials. Current Medicinal Chemistry, 17, 2070-2095. http://dx.doi.org/10.2174/092986710791233689

[6] Sack, R.L., Brandes, R.W., Kendall, A.R. and Lewy, A.J. (2000) Entrainment of Free-Running Circadian Rhythms by Melatonin in Blind People. New England Journal of Medicine, 343, 1070-1077. http://dx.doi.org/10.1056/NEJM200010123431503

[7] Boudreau, E.A., Johnson, K.P., Jackman, A.R., Blancato, J., Huizing, M., Bendavid, C., Jones, M.P., Chandrasekharappa, S.C., Lewy, A.J., Smith, A.C.M. and Magenis, R.E. (2009) Review of Disrupted Sleep Patterns in Smith-Magenis Syndrome and Normal Melatonin Secretion in a Patient with an Atypical Interstitial 17p11.2 Deletion. American Journal of Medical Genetics, 149, 1382-1391. http://dx.doi.org/10.1002/ajmg.a.32846

[8] Simonneaux, V. and Ribelayga, C. (2003) Generation of the Melatonin Endocrine Message in Mammals: A Review of the Complex Regulation of Melatonin Synthesis by Norepinephrine, Peptides, and Other Pineal Transmitters. Pharmacological Reviews, 55, 325-395. http://dx.doi.org/10.1124/pr.55.2.2

[9] Reiter, R.J., Tan, D.X. and Fuentes-Broto, L. (2010) Melatonin: A Multitasking Molecule. Progress in Brain Research, 181, 127-151. http://dx.doi.org/10.1016/S0079-6123(08)81008-4

[10] Chemical Reactions. http://www.ch.ic.ac.uk/local/projects/s_thipayang/synth.html

[11] Grivas, T.B. and Savvidou, O.D. (2007) Melatonin the "Light of Night" in Human Biology and Adolescent Idiopathic Scoliosis. Scoliosis, 2, 6. http://dx.doi.org/10.1186/1748-7161-2-6

[12] Lam, R.W. and Levitan, R.D. (2000) Pathophysiology of Seasonal Affective Disorder: A Review. Journal of Psychiatry Neuroscience, 25, 469-480.

[13] Butler, M.P., Turner, K.W., Park, J.H., Schoomer, E.E., Zucker, I. and Gorman, M.R. (2010) Seasonal Regulation of Reproduction: Altered Role of Melatonin under Naturalistic Conditions in Hamsters. Proceedings of the Royal Society, 277, 2867-2874.

[14] Thomas, D.R. and Miles, A. (1989) Melatonin Secretion and Age. Biological Psychiatry, 25, 365-367. http://dx.doi.org/10.1016/0006-3223(89)90187-X

[15] Cardinali, D.P., Furio, A.M. and Brusco, L.I. (2010) Clinical Aspects of Melatonin Intervention in Alzheimers Disease Progression. Current Neuropharmacology, 8, 218-227. http://dx.doi.org/10.2174/157015910792246209

[16] Chan, K.H. and Wong, Y.H. (2013) A Molecular and Chemical Perspective in Defining Melatonin Receptor Subtype Selectivity. International Journal of Molecular Sciences, 14, 18385-18406. http://dx.doi.org/10.3390/ijms140918385

[17] Masana, M.I., Doolen, S., Ersahin, C., Al-Ghoul, W.M., Duckles, S.P., Dubocovich, M.L. and Krause, D.N. (2002) MT2 Melatonin Receptors Are Present and Functional in Rat Caudal Artery. Journal of Pharmacology and Experimental, 302, 1295-1302. http://dx.doi.org/10.1124/jpet.302.3.1295

[18] Dubocovich, M.L., Delagrange, P., Krause, D.N., Sugden, D., Cardinali, D.P. and Olcese, J. (2010) International Union of Basic and Clinical Pharmacology. LXXV. Nomenclature, Classification and Pharmacology of G Protein-Coupled Melatonin Receptors. Pharmacological Reviews, 62, 343-380. http://dx.doi.org/10.1124/pr.110.002832

[19] Li, D.Y., Smith, D.G., Hardeland, R., Yang, M.Y., Xu, H.L., Zhang, L., Yin, H.D. and Zhu, Q. (2013) Melatonin Re- 
ceptor Genes in Vertebrates. International Journal of Molecular Sciences, 14, 11208-11223. http://dx.doi.org/10.3390/ijms140611208

[20] Tunstall, R.R., Shukla, P., Grazul-Bilska, A., Sun, C. and O’Rourke, S.T. (2011) MT2 Receptors Mediate the Inhibitory Effects of Melatonin on Nitric Oxide-Induced Relaxation of Porcine Isolated Coronary Arteries. Journal of Pharmacology and Experimental Therapeutics, 336, 127-133. http://dx.doi.org/10.1124/jpet.110.174482

[21] Malpaux, B., Tricoire, H., Mailliet, F., Daveau, A., Migaud, M., Skinner, D.C., Pelletier, J. and Chemineau, P. (2002) Melatonin and Seasonal Reproduction: Understanding the Neuroendocrine Mechanisms Using the Sheep as a Model. Reproduction (Cambridge, England) Supplement, 59, 167-179.

[22] Ram, P.T., Dai, J., Yuan, L., Dong, C., Kiefer, T.L., Lai, L. and Hill, S.M. (2002) Involvement of the Mt1 Melatonin Receptor in Human Breast Cancer. Cancer Letters, 179, 141-150. http://dx.doi.org/10.1016/S0304-3835(01)00873-4

[23] Srinivasan, V., Pandi-Perumal, S.R., Brzezinski, A., Bhatnagar, K.P. and Cardinali, D.P. (2011) Melatonin, Immune Function and Cancer. Recent Patents on Endocrine, Metabolic \& Immune Drug Discovery, 5, 109-123.

[24] Witt-Enderby, P.A., Bennett, J., Jarzynka, M.J., Firestine, S. and Melissa, A. (2003) Melatonin Receptors and Their Regulation: Biochemical and Structural Mechanisms. Life Sciences, 72, 2183-2198. http://dx.doi.org/10.1016/S0024-3205(03)00098-5

[25] Rosales-Corral, S.A. Acuña-Castroviejo, D., Coto-Montes, A., Boga, J.A., Manchester, L.C., Fuentes-Broto, L., Korkmaz, A., Ma, S., Tan, D.X. and Reiter, R.J. (2012) Alzheimer’s Disease: Pathological Mechanisms and the Beneficial Role of Melatonin. Journal of Pineal Research, 52, 167-202. http://dx.doi.org/10.1111/j.1600-079X.2011.00937.x

[26] Radogna, F., Diederich, M. and Ghibelli, L. (2010) Melatonin: A Pleiotropic Molecule Regulating Inflammation. Biochemical Pharmacology, 80, 1844-1852. http://dx.doi.org/10.1016/j.bcp.2010.07.041

[27] Di Bella, G., Mascia, F., Gualano, L. and Di Bella, L. (2013) Melatonin Anticancer Effects: Review. International Journal of Molecular Sciences, 14, 2410-2430. http://dx.doi.org/10.3390/ijms14022410

[28] Soto-Vega, E., Meza, I., Ramírez-Rodríguez, G. and Benitez-King, G. (2004) Melatonin Stimulates Calmodulin Phosphorylation by Protein Kinase C. Journal of Pineal Research, 37, 98-106. http://dx.doi.org/10.1111/j.1600-079X.2004.00141.x

[29] Srinivasan, V., Pandi-Perumal, S.R., Brown, G.M., Cardinali, D.P., Spence, D.W. and Hardeland, R. (2011) Melatonin: A Pleiotropic, Orchestrating Regulator Molecule. Progress in Neurobiology, 93, 350-384. http://dx.doi.org/10.1016/j.pneurobio.2010.12.004

[30] Acuña-Castroviejo, D., Martín, M., Macías, M., Escames, G., León, J., Khaldy, H. and Reiter, R.J. (2001) Melatonin, Mitochondria and Cellular Bioenergetics. Journal of Pineal Research, 30, 65-74. http://dx.doi.org/10.1034/j.1600-079X.2001.300201.x

[31] Dilek, M., Naziroğlu, M., Oral, H.B., Ovey, I.S., Küçükayaz, M., Mungan, M.T., Kara, H.Y. and Sütçü, R. (2010) Melatonin Modulates Hippocampus NMDA Receptors, Blood and Brain Oxidative Stress Levels in Ovariectomized Rats. Journal of Membrane Biology, 233, 135-142. http://dx.doi.org/10.1007/s00232-010-9233-x

[32] Reiter, R.J., Tan, D.X., Osuna, C. and Gitto, E. (2000) Actions of Melatonin in the Reduction of Oxidative Stress. Journal of Biomedical Science, 7, 444-448. http://dx.doi.org/10.1007/BF02253360

[33] Baldassarri1, V., Salucci1, S., Curzi1, D., Burattini, S. and Falcieri, E. (2012) Cytoprotective Effects of Melatonin in C2C12 Skeletal Muscle Cells: A Multiple Technical Approach. Italian Journal of Anatomy and Embryology, $117,15$.

[34] Parlakpinar, H., Sahna, E., Ozer, M.K., Ozugurlu, F., Vardi, N. and Acet, A. (2002) Physiological and Pharmacological Concentrations of Melatonin Protect against Cisplatin-Induced Acute Renal Toxicity. Journal of Pineal Research, 33, 161-167. http://dx.doi.org/10.1034/j.1600-079X.2002.02910.x

[35] Poeggeler, B., Saarela, S., Reiter, R.J., Tan, D.-X., Chen, L.-D., Manchester, L.C. and Barlow-Walden, L.R. (2006) Melatonin-A Highly Potent Endogenous Radical Scavenger and Electron Donor: New Aspects of the Oxidation Chemistry of This Indole Accessed in Vitro. Annals of the New York Academy of Sciences, 738, 419-420. http://dx.doi.org/10.1111/j.1749-6632.1994.tb21831.x

[36] Shirinzadeh, H., Eren, B., Gurer-Orhan, H., Suzen, S. and Özden, S. (2010) Novel Indole-Based Analogs of Melatonin: Synthesis and in Vitro Antioxidant Activity Studies. Molecules, 15, 2187-2202. http://dx.doi.org/10.3390/molecules15042187

[37] Turjanski, A.G., Saenz, D.A., Doctorovich, F., Estrin, D.A. and Rosenstein, R.E. (2001) Nitrosation of Melatonin by Nitric Oxide: A Computational Study. Journal of Pineal Research, 31, 97-101. http://dx.doi.org/10.1034/j.1600-079x.2001.310201.x

[38] Blanchard, B., Pompon, D. and Ducroq, C. (2000) Nitrosation of Melatonin by Nitric Oxide and Peroxynitrite. Journal of Pineal Research, 29, 184-192. http://dx.doi.org/10.1034/j.1600-079X.2000.290308.X

[39] Bondy, S.C., Lahiri, D.K., Perreau, V.M., Sharman, K.Z., Campbell, A., Zhou, J. and Sharman, E.H. (2004) Retarda- 
tion of Brain Aging by Chronic Treatment with Melatonin. Annals of the New York Academy of Sciences, 1035, 197-215.

[40] du Plessis, S.S., Hagenaar, K. and Lampiao, F. (2010) The in Vitro Effects of Melatonin on Human Sperm Function and Its Scavenging Activities on NO and ROS. Andrologia, 42, 112-116.

http://dx.doi.org/10.1111/j.1439-0272.2009.00964.x

[41] Bonnefont-Rousselot, D. and Collin, F. (2010) Melatonin: Action as Antioxidant and Potential Applications in Human Disease and Aging. Toxicology, 278, 55-67. http://dx.doi.org/10.1016/j.tox.2010.04.008

[42] Barja, G. (2004) Free Radicals and Aging. Trends in Neurosciences, 27, 595-600. http://dx.doi.org/10.1016/j.tins.2004.07.005

[43] Wu, Y.H. and Dick, F.S. (2005) The Human Pineal Gland and Melatonin in Aging and Alzheimer's Disease. Journal of Pineal Research, 38, 145-152. http://dx.doi.org/10.1111/j.1600-079X.2004.00196.x

[44] Velázquez-Paniagua, M., Contreras-Pérez, R., Gómez-Vidales, V., Meneses-Pérez, M.A. and Prieto-Gómez, B. (2007) Melatonin's Effects on Free Radical Levels in Rat Hippocampus, Measured by Electronic Paramagnetic Resonance. Pharmacologyonline, 1, 170-175.

[45] Prieto-Gomez, B., Velazquez-Paniagua, M., Olivos-Cisneros, L., Reyes-Vazquez, C., Jimenez-Trejo, F., Reyes, M.E., Mendoza-Torreblanca, J. and Gutierrez-Ospina, G. (2008) Melatonin Attenuates the Decrement of Dendritic Protein MAP-2 Immuno-Staining in the Hippocampal CA1 and CA3 Fields of the Aging Male Rat. Neuroscience Letters, 448, 56-61. http://dx.doi.org/10.1016/j.neulet.2008.10.041

[46] Perez-Torres, D., Reyes-Vázquez, C., Velázquez-Paniagua, M. and Prieto-Gómez, B. (2014) Melatonin Changes the Electrical Spontaneous Activity of Hippocampal Rat Neurons at Different Ages. Advances in Aging Research, 3, 29-34. http://dx.doi.org/10.4236/aar.2014.31006

[47] Rameswhar, S. and Sharma, D. (2005) Electrophysiology Ageing of the Brain and Pharmacology of Ageing. In: Thakur, M.K. and Prasad, S., Eds., Molecular and Cellular Neurobiology, Narosa Publishing House Private Limited, New Delhi, 135-148.

[48] Reiter, R.J., Tan, D.X., Osuna, C. and Gitto, E. (2000) Actions of Melatonin in the Reduction of Oxidative Stress. A Review. Journal of Biomedical Science, 7, 444-458. http://dx.doi.org/10.1007/BF02253360

[49] Reiter, R.J., Tan, D.X., Mayo, J.C., Sainz, R.M., Leon, J. and Czarnocki, Z. (2003) Melatonin as an Antioxidant: Biochemical Mechanisms and Pathophysiological Implications in Humans. Acta Biochimica Polonica, 50, 1129-1146.

[50] Bharti, V.K. and Srivastava, R.S. (2009) Pineal Proteins Upregulate Specific Antioxidant Defense Systems in the Brain. Oxidative Medicine and Cellular Longevity, 2, 88-92. http://dx.doi.org/10.4161/oxim.2.2.8361

[51] Hardeland, R. (2009) Neuroprotection by Radical Avoidance: Search for Suitable Agents. Molecules, 14, $5054-5102$. http://dx.doi.org/10.3390/molecules14125054

[52] Mayo, J.C., Tan, D.X., Sainz, R.M., Natarajan, M., Lopez-Burillo, S. and Reiter, R.J. (2003) Protection against Oxidative Protein Damage Induced by Metal-Catalyzed Reaction or alkylperoxyl Radicals: Comparative Effects of Melatonin and Other Antioxidants. Biochimica et Biophysica Acta, 1620, 139-150. http://dx.doi.org/10.1016/S0304-4165(02)00527-5

[53] Samir, M., Sawhney, G. and Pandhi, P. (2004) The Therapeutic Potential of Melatonin: A Review of the Science. Archive of Medscape General Medicine, 6, 46.

[54] Vinogradova1, A.I., Anisimov, V.N., Bukalev1, A.N., Ilyukha1, V.A., Khizhkin, E.A., Lotosh, T.A., Semenchenko, A.V. and Zabezhinski, M.A. (2010) Circadian Disruption Induced by Light-at-Night Accelerates Aging and Promotes Tumorigenesis in Young but Not in Old Rats. Aging, 2, 82-92.

[55] http://www.lef.org/

[56] Bonmati-Carrion, M.A., Álvarez-Sánchez, N., Hardeland, R., Madrid, J.A. and Rol, M.A. (2013) A Comparison of B16 Melanoma Cells and 3T3 Fibroblasts Concerning Cell Viability and ROS Production in the Presence of Melatonin, Tested over a Wide Range of Concentrations. International Journal of Molecular Sciences, 14, 3901-3920. http://dx.doi.org/10.3390/ijms14023901

[57] Voordouw, B.C., Euser, R., Verdonk, R.E., Alberda, B.T., de Jong, F.H., Drogendijk, A.C., Fauser, B.C. and Cohen, M. (2013) Melatonin and Melatonin-Progestin Combinations Alter Pituitary-Ovarian Function in Women and Can Inhibit Ovulation. http://dx.doi.org/10.1210/jcem.74.1.1727807

[58] Gwayi, N. and Bernard, R.T. (2002) The Effects of Melatonin on Sperm Motility in Vitro in Wistar Rats. Andrologia, 34, 391-396. http://dx.doi.org/10.1046/j.1439-0272.2002.00522.x

[59] Gutiérrez-Ruiz, J., Granados-Canseco, F., Martínez-Esparza, C., Velázquez-Paniagua, M. and Prieto-Gómez, B. (2006) Chronic Melatonin Application Modifies the Cytoarchitecture of Testis and Decreases the Sperm Number in Wistar Rat. Pharmacologyonline, 3, 422-427. 
Scientific Research Publishing (SCIRP) is one of the largest Open Access journal publishers. It is currently publishing more than 200 open access, online, peer-reviewed journals covering a wide range of academic disciplines. SCIRP serves the worldwide academic communities and contributes to the progress and application of science with its publication.

Other selected journals from SCIRP are listed as below. Submit your manuscript to us via either submit@scirp.org or Online Submission Portal.
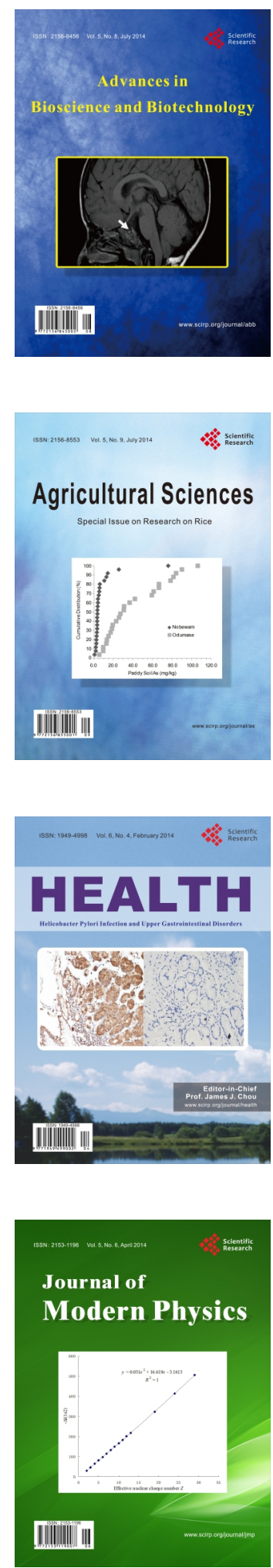
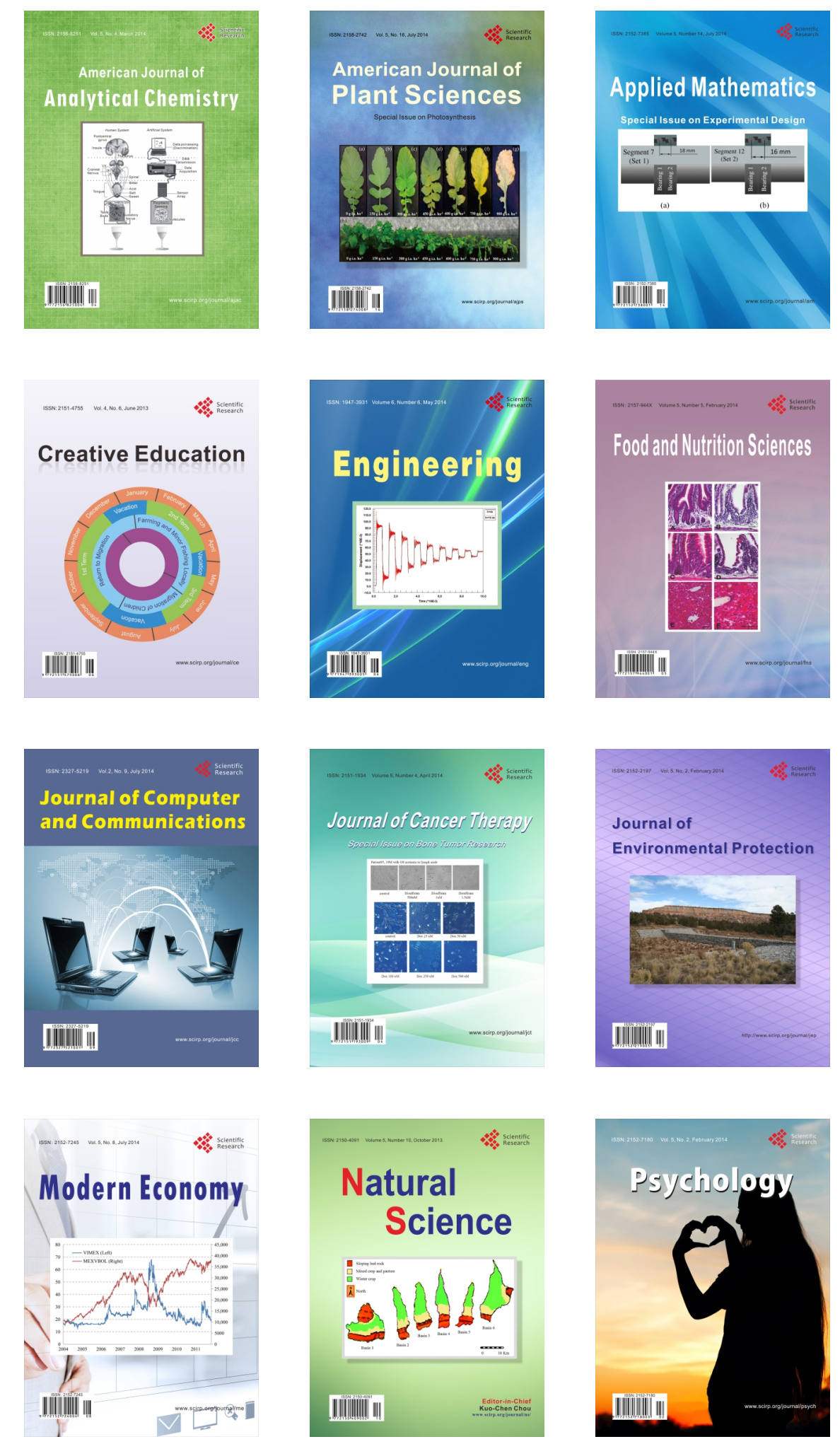